\title{
THE EFFECT OF ACETAZOLAMIDE ON THE RETINAL CIRCULATION
}

\author{
S. M. B. RASSAM, V. PATEL and E. M. KOHNER \\ London
}

\begin{abstract}
SUMMARY
The effect of the carbonic anhydrase inhibitor, acetazolamide, on the retinal circulation was studied in 10 healthy volunteers. Acetazolamide was administered intravenously at a dose of $500 \mathrm{mg}$. Retinal blood flow was determined from red cell velocity using laser Doppler velocimetry and vessel diameter measurement using computerised digital image analysis of monochromatic fundus photographs. There was a significant increase in retinal blood flow at 30 minutes and 60 minutes after acetazolamide injection $(p=0.002)$. Retinal vessels showed vasodilatation reaching significant levels 60 minutes after the injection $(\boldsymbol{p}<\mathbf{0 . 0 3})$. An increase in red cell velocity was observed at 30 and 60 minutes $(p<0.002)$. A significant reduction in intraocular pressure occurred at 30 and 60 minutes after the injection $(p<0.001)$. The mechanisms responsible for the increase in retinal blood flow acted via significant increases in perfusion pressure $(p<0.05)$, red cell velocity $(p<0.002)$ and retinal vessel dilatation $(p<0.03)$. An increase in tissue $\mathrm{PCO}_{2}$ and a reduction in $\mathrm{pH}$ are thought to be responsible for the vascular dilatation. The increase in retinal blood flow with acetazolamide may serve to limit optic disc and retinal ischaemia in acute glaucoma and central retinal artery occlusion respectively.
\end{abstract}

Acetazolamide is a carbonic anhydrase inhibitor. It reduces intraocular pressure and is therefore used extensively in ophthalmological clinical practice for the management of glaucoma. It has also been advocated in the management of retinal artery occlusion through its postulated effect of increasing retinal blood flow. ${ }^{1}$ The efficacy and the exact effect of acetazolamide on the human ocular circulation have not been determined previously as direct non-invasive measurements of retinal blood flow have not been possible. Most of the effects of acetazolamide on the ocular circulation have been extrapolated from work on the cerebral circulation, since many

From: Diabetic Retinopathy Unit, Hammersmith Hospital, London, UK.

Correspondence to: Professor E. M. Kohner, Diabetic Retinopathy Unit, Department of Medicine, RPMS, Hammersmith Hospital, Du Cane Road, London W12 0NN, UK. techniques are available for studying the cerebral circulation including ${ }^{133} \mathrm{Xe}$ clearance, ${ }^{2}$ pulsed ultrasound Doppler system $^{3}$ and single-photon emission computed tomography. ${ }^{4}$

Studies of the effect of $1000 \mathrm{mg}$ acetazolamide on the cerebral circulation in humans have shown a rise of $38 \%$ in cerebral blood flow after an oral dose ${ }^{5}$ and $70 \%$ after the same dose given intravenously. ${ }^{2}$ This increase in cerebral blood flow was due mainly to cerebral vascular dilatation. Acetazolamide was found to increase the partial pressure of carbon dioxide $\left(\mathrm{PCO}_{2}\right)$ and to reduce $\mathrm{pH}$ in the cerebral extracellular fluid. ${ }^{6}$ It was then suggested that the direct effect of acetazolamide on tissue $\mathrm{PCO}_{2}$ and $\mathrm{pH}$ is a potent stimulus for vasodilatation.

In the eye, increasing $\mathrm{PCO}_{2}$ in the retinal circulation has also been shown to produce retinal vascular vasodilatation in monkeys. ${ }^{7}$ The effect of acetazolamide on the retinal circulation, however, is not confined to the metabolic changes. Along with the metabolic effects as described in the cerebral circulation, acetazolamide reduces intraocular pressure which thus has a further effect on retinal perfusion pressure.

The retinal circulation is unique in that it has no autonomic innervation ${ }^{8,9}$ and therefore regulation of blood flow is entirely dependent on autoregulation. In the strictest sense, autoregulation is defined as the ability of the vessels to maintain a constant flow to the tissues under conditions of varying perfusion pressure. ${ }^{10}$ This definition was later expanded to include the changes in the vascular haemodynamics to support the metabolic needs of the tissues. ${ }^{11}$

With the advent of the laser Doppler velocimeter as a direct and non-invasive means of measuring retinal blood flow, we set out to study the effect of acetazolamide on retinal haemodynamics.

\section{MATERIALS AND METHOD}

\section{Subjects}

Ten healthy volunteers, age range $24-37$ years (mean \pm $\mathrm{SD}, 31.4 \pm 4.53$ years) were recruited. All subjects had 
normal physical examination, visual acuity of $6 / 12$ or better unaided, normal ocular examination and normal intraocular pressures. Informed consent was obtained from the study subjects after a detailed explanation of the protocol. Approval from the local ethics committee was granted in accordance with the principles laid down by the Helsinki Declaration.

\section{Study Design}

The study took place in a comfortable laboratory environment. Pupillary dilatation was achieved with tropicamide $0.5 \%$ eye drops. After a resting period of approximately 30 minutes, baseline measurements of blood pressure, laser Doppler velocimetry (see below), retinal photographs and intraocular pressure measurements were obtained. Acetazolamide $500 \mathrm{mg}$ diluted in $10 \mathrm{ml}$ normal saline was injected through an arm vein. Blood pressure, laser Doppler velocimetry, retinal photographs and intraocular pressure measurements were repeated 30 and 60 minutes after the injection.

In 4 of the subjects studied, the study was repeated on a different day using only $10 \mathrm{ml}$ normal saline. This was to exclude any effects of the procedure on retinal haemodynamics.

\section{Blood Velocity Measurement}

Retinal blood flow was determined from red cell velocity using bidirectional laser Doppler velocimetry (Oculix, Philadelphia, USA). ${ }^{12}$ This technique utilises the shift in frequency produced when a monochromatic laser beam from a helium-neon laser $(632.8 \mathrm{~nm}$, irradiance $80 \mathrm{~mW} /$ $\mathrm{cm}^{2}$ ) is reflected from moving red blood cells in the retinal vessels. This shift in frequency is directly proportional to the red cell velocity. The frequency-shifted light is collected by a pair of photoreceptors and stored on the hard disc of a minicomputer (Masscomp, Massachusetts, USA); the collected data were analysed later in a randomised masked fashion. Since flow of blood in a vessel is parabolic, ${ }^{13}$ only the maximally shifted frequency was used, representing the maximal centreline red cell velocity $\left(V_{\max }\right)$.

\section{Vessel Diameter Measurement}

Vessel dimaeter $(D)$ was determined from monochromatic fundus photographs. The photographs were taken with a $30^{\circ}$ Zeiss fundus camera (Zeiss, Oberkochen, Germany) linked to an electrocardiographic monitor through a time delay device. This device triggered the shutter of the camera at a predetermined point from the electrocardiographic R-wave, thus allowing all the fundus photographs to be taken in mid-diastole. This technique eliminates the effect of pulsatility on the variation in vessel diameter measurements. ${ }^{14}$ The film used was Kodak Technical Pan film (Kodak, Rochester, NY, USA) and the photographs were taken through a red-free $570 \mathrm{~nm}$ interference filter to increase the resolution of the vasculature. ${ }^{15}$ The fundus photographs were projected through a video camera, digitised by an image analysis computer (Context Vision,
Linköping, Sweden) and projected on a $512 \times 512$ pixel screen. From the images, retinal vessel diameters were determined using the half-height of the transmittance profiles. ${ }^{16}$ The magnifying power of the fundus camera on retinal images is dependent on the ocular refraction. Therefore, vessel diameter measurements were corrected for the magnification of the camera and the ocular refraction using tables adopted from the work of Bengtsson and Krakau. ${ }^{17}$ Three photographs were taken at each time point during the study and three vessel diameter measurements from each of the three photographs were averaged.

Blood flow in the superior and inferior temporal veins is similar, as shown by Feke et al. ${ }^{18}$ and Riva et al. ${ }^{19}$ using the laser Doppler technique. Therefore, either the superior or the inferior temporal veins were chosen to measure retinal blood flow, within one disc diameter from the disc edge before any bifurcation. Flow in the temporal retina is greater than in the nasal retina due to the higher metabolic activity at the macula and the temporal retina being 20-25\% larger than the nasal retina. ${ }^{19,20}$ Venous flow was chosen rather than arterial flow because of the limitations of the instrumentation. ${ }^{18}$ Flow in retinal veins has been shown to be similar to that in the corresponding retinal arteries, ${ }^{18,19}$ adhering to the theory of conservation since the retinal circulation lacks lymphatic flow.

A polaroid fundus photograph was obtained to mark the exact position of the velocity measurement on the vein. This later provided a reference point for the site of vessel diameter determination.

\section{Volumetric Flow Rate}

The volumetric flow rate $(Q)$ was calculated by multiplying the mean red cell velocity $\left(V_{\text {mean }}\right)$ by the cross-sectional area $(A)$ of the vessel:

$$
Q=V_{\text {mean }} \cdot A
$$

To determine the mean red cell velocity, the maximal centreline red cell velocity $\left(V_{\max }\right)$ was divided by a factor of 1.6 according to the work of Baker and Wayland ${ }^{13}$ and Damon and Duling, ${ }^{21}$ since blood does not flow like a perfect Newtonian fluid. The cross-sectional area of the vessel was determined from the vessel diameter $(D)$. The formula for calculating the flow therefore becomes:

$$
Q=\frac{V_{\max }}{1.6} \cdot \pi \cdot \frac{D^{2}}{4}
$$

\section{Retinal Perfusion Pressure}

Blood pressure was determined using a Takeda automatic digital blood pressure meter (A\&D Engineering, California, USA) calibrated with a random-zero mercury sphygmomanometer. Intraocular pressure was measured with Goldmann applanation tonometry. Mean arterial blood pressure (MAP) was calculated by adding the diastolic blood pressure $\left(\mathrm{BP}_{\mathrm{DIA}}\right)$ to one-third the difference between the systolic $\left(\mathrm{BP}_{\mathrm{SYS}}\right)$ and diastolic blood pressures $\left[\mathrm{MAP}=1 / 3\left(\mathrm{BP}_{\mathrm{SYS}}-\mathrm{BP}_{\mathrm{DIA}}\right)+\mathrm{BP}_{\mathrm{DIA}}\right]$. Perfusion pressure (PP) was determined by subtracting the intraocular 
Table I. Results for acetazolamide injection

\begin{tabular}{|c|c|c|c|c|c|c|c|c|}
\hline & \multicolumn{2}{|c|}{$0 \mathrm{~min}$} & \multicolumn{3}{|c|}{$30 \mathrm{~min}$} & \multicolumn{3}{|c|}{$60 \mathrm{~min}$} \\
\hline & Mean & SD & Mean & SD & $p$ & Mean & SD & $p$ \\
\hline $\mathrm{BP}_{\text {SYS }}(\mathrm{mmHg})$ & 110.00 & $(8.92)$ & 109.70 & (11.62) & - & 105.80 & $(8.82)$ & - \\
\hline $\mathrm{BP}_{\mathrm{DIA}}(\mathrm{mmHg})$ & 68.10 & $(9.43)$ & 66.75 & $(9.22)$ & - & 64.30 & $(8.07)$ & 0.02 \\
\hline Pulse (beats/min) & 64.20 & (12.94) & 62.30 & (10.34) & - & 62.60 & (11.73) & - \\
\hline MAP (mmHg) & 82.07 & $(7.77)$ & 81.03 & $(8.50)$ & - & 78.13 & $(7.28)$ & 0.01 \\
\hline IOP (mmHg) & 16.40 & $(4.12)$ & 12.60 & $(3.81)$ & $<0.001$ & 11.00 & (3.56) & $<0.001$ \\
\hline $\mathrm{PP}(\mathrm{mmHg})$ & 38.31 & $(4.80)$ & 41.42 & $(5.91)$ & $<0.001$ & 41.09 & $(3.92)$ & 0.019 \\
\hline Diameter $(\mu \mathrm{m})$ & 146.50 & (22.18) & 148.99 & (23.07) & - & 149.22 & (22.60) & 0.029 \\
\hline Velocity $(\mathrm{cm} / \mathrm{s})$ & 1.60 & $(0.26)$ & 2.09 & $(0.33)$ & $<0.001$ & 2.05 & $(0.41)$ & 0.002 \\
\hline Flow $(\mu \mathrm{l} / \mathrm{min})$ & 10.29 & (3.53) & 14.10 & $(5.34)$ & $<0.002$ & 13.80 & $(5.25)$ & 0.001 \\
\hline
\end{tabular}

Data at 30 and 60 minutes are compared with baseline $(0 \mathrm{~min})$. Results are expressed as mean \pm SD.

$\mathrm{BP}_{\mathrm{SYS}}$, systolic blood pressure; $\mathrm{BP}_{\mathrm{DIA}}$, diastolic blood pressure; MAP, mean arterial blood pressure; IOP, intraocular pressure; $\mathrm{PP}$, perfusion pressure.

pressure (IOP) from the two-thirds mean arterial blood pressure $(\mathrm{PP}=2 / 3 \mathrm{MAP}-\mathrm{IOP}){ }^{22}$

\section{Statistical Analysis}

Results are expressed as mean \pm SD. Retinal haemodynamic changes at 30 and 60 minutes after injection of acetazolamide were compared with baseline haemodynamic parameters before the injection. One-way analysis of vari-

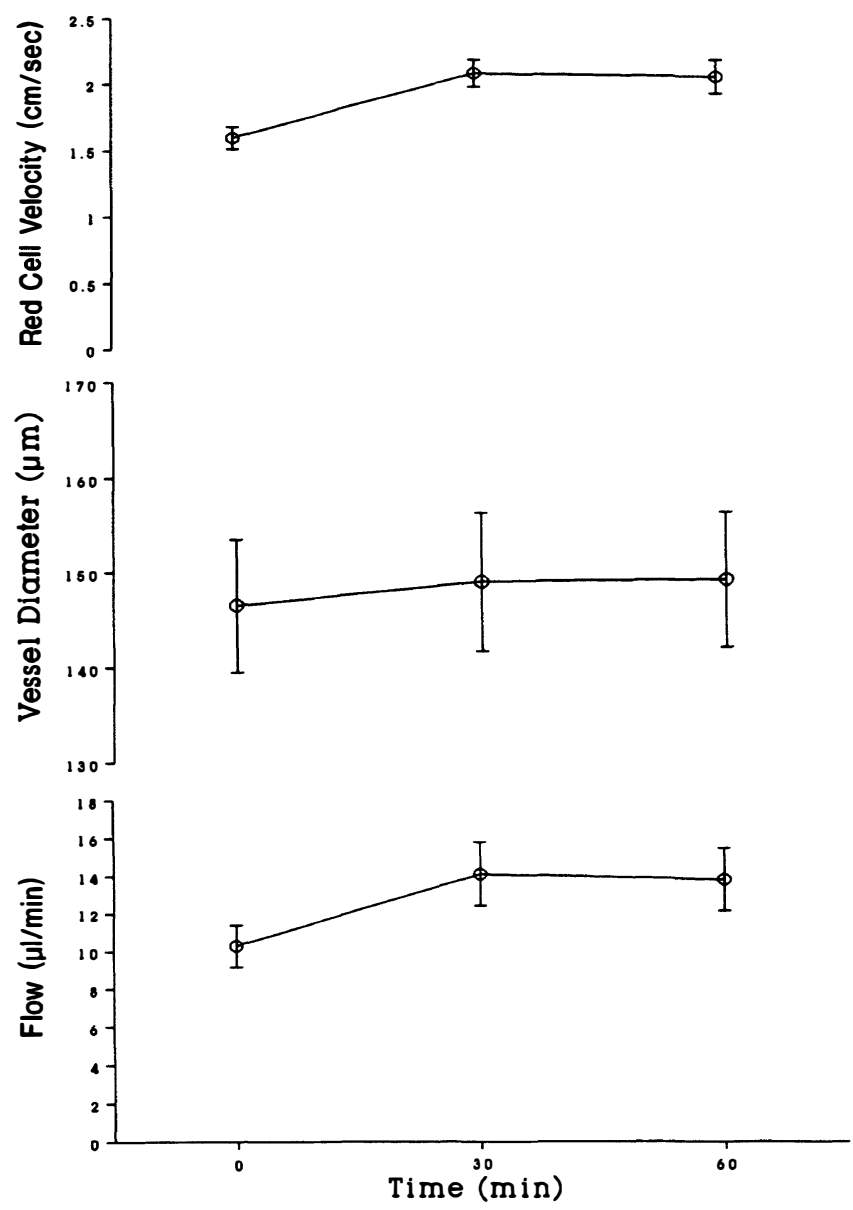

Fig. 1. Red cell velocity, vessel diameter and retinal blood flow after acetazolamide injection. Results are expressed as mean \pm SEM. Significant vasodilatation occurred 60 minutes after acetazolamide injection $(\mathrm{p}<0.03)$; red cell velocity is significantly increased at 30 minutes and 60 minutes $(\mathrm{p}<0.002)$; and retinal blood flow is significantly increased at 30 minutes and 60 minutes $(\mathrm{p}<0.002)$. ance was used to detect the presence of significant differences. The level of significance was then determined using a paired Student's $t$-test (Oxstat II, Microsoft, 1985). Results were considered to be statistically significant when $p<0.05$.

\section{RESULTS}

Results for the effect of acetazolamide injection are shown in Table I. There was significant reduction in intraocular pressure by approximately $4 \mathrm{mmHg}(23.2 \%, p<0.001)$ at 30 minutes and approximately $5 \mathrm{mmHg}(32.9 \%$, $p<0.001$ ) at 60 minutes after intravenous injection of acetazolamide. The mean arterial blood pressure was not significantly affected at 30 minutes but was decreased 60 minutes after the injection $(p=0.01)$, secondary to a significant reduction in diastolic blood pressure $(p=0.02)$. A significant increase in retinal perfusion pressure $(p<0.02)$ at both 30 and 60 minutes after the injection occurred despite a small fall in mean arterial blood pressure as a consequence of the decrease in intraocular pressure. A trend towards venous dilatation after acetazolamide injection was observed at 30 minutes and reached statistical significance at 60 minutes $(p=0.029)$. A significant increase in red cell velocity was seen after the injection of acetazolamide $(p<0.002)$. As a result of the changes in vessel diameter and red cell velocity, the volumetric flow rate in the retina showed a significant rise by $37.03 \%$ at 30 minutes $(p=0.002)$ and by $34.11 \%$ at 60 minutes $(p=0.001)$ after the injection (Fig. 1).

Data for the normal saline group are summarised in Table II. There was no change in any of the parameters measured after the injection of $10 \mathrm{ml}$ normal saline.

\section{DISCUSSION}

This study defines the haemodynamic changes in the retinal circulation in response to ocular carbonic anhydrase inhibition by acetazolamide, and describes the consequent changes in the regulatory mechanisms of the retinal vessels in view of these haemodynamic changes.

Acetazolamide is a potent carbonic anhydrase inhibitor. Full physiological inhibition of carbonic anhydrase occurs in most tissues at doses greater than $10 \mathrm{mg} / \mathrm{kg}$ in man. In the red blood cell, carbonic anhydrase inhibition occurs within 1 minute of acetazolamide injection. ${ }^{23}$ In this study 
Table II. Results for normal saline injection

\begin{tabular}{|c|c|c|c|c|c|c|}
\hline & \multicolumn{2}{|c|}{$0 \mathrm{~min}$} & \multicolumn{2}{|c|}{$30 \mathrm{~min}$} & \multicolumn{2}{|c|}{$60 \mathrm{~min}$} \\
\hline & Mean & SD & Mean & SD & Mean & SD \\
\hline $\mathrm{BP}_{\mathrm{SYS}}(\mathrm{mmHg})$ & 113.00 & $(7.62)$ & 109.50 & $(9.68)$ & 113.75 & $(6.85)$ \\
\hline $\mathrm{BP}_{\mathrm{DIA}}(\mathrm{mmHg})$ & 63.75 & $(8.34)$ & 62.50 & (11.73) & 67.75 & (8.06) \\
\hline Pulse (beats/min) & 59.25 & (7.63) & 60.50 & $(9.57)$ & 58.50 & $(8.06)$ \\
\hline $\mathrm{MAP}(\mathrm{mmHg})$ & 80.17 & $(7.90)$ & 78.17 & (10.53) & 83.33 & $(7.36)$ \\
\hline $\mathrm{IOP}(\mathrm{mmHg})$ & 16.75 & $(2.50)$ & 15.75 & $(2.87)$ & 16.75 & $(1.50)$ \\
\hline $\mathrm{PP}(\mathrm{mmHg})$ & 36.67 & $(4.09)$ & 36.36 & $(5.16)$ & 38.81 & $(3.80)$ \\
\hline Diameter $(\mu \mathrm{m})$ & 159.10 & $(18.85)$ & 161.18 & $(24.82)$ & 160.76 & (21.87) \\
\hline Velocity $(\mathrm{cm} / \mathrm{s})$ & 1.69 & $(0.56)$ & 1.68 & $(0.42)$ & 1.73 & $(0.54)$ \\
\hline Flow $(\mu \mathrm{l} / \mathrm{min})$ & 12.80 & $(5.22)$ & 12.81 & (3.65) & 13.20 & $(4.50)$ \\
\hline
\end{tabular}

Results are expressed as mean \pm SD. Abbreviations as in Table I.

acetazolamide was used at an average dose of $7 \mathrm{mg} / \mathrm{kg}$; therefore, complete inhibition of carbonic anhydrase may not have occurred.

Carbonic anhydrase in the red blood cell is responsible for $70 \%$ of the carbon dioxide $\left(\mathrm{CO}_{2}\right)$ carrying capacity from the tissues to the lung. $\mathrm{CO}_{2}$ originating from the tissue metabolism diffuses out of the tissues into the blood (Fig. 2). In the red blood cells, $\mathrm{CO}_{2}$ combines with water in the presence of carbonic anhydrase to form bicarbonate $\left(\mathrm{HCO}_{3}^{-}\right)$ions and hydrogen $\left(\mathrm{H}^{+}\right)$ions. While the $\mathrm{HCO}_{3}^{-}$

\section{Blood}

\section{Endothelial Cells}

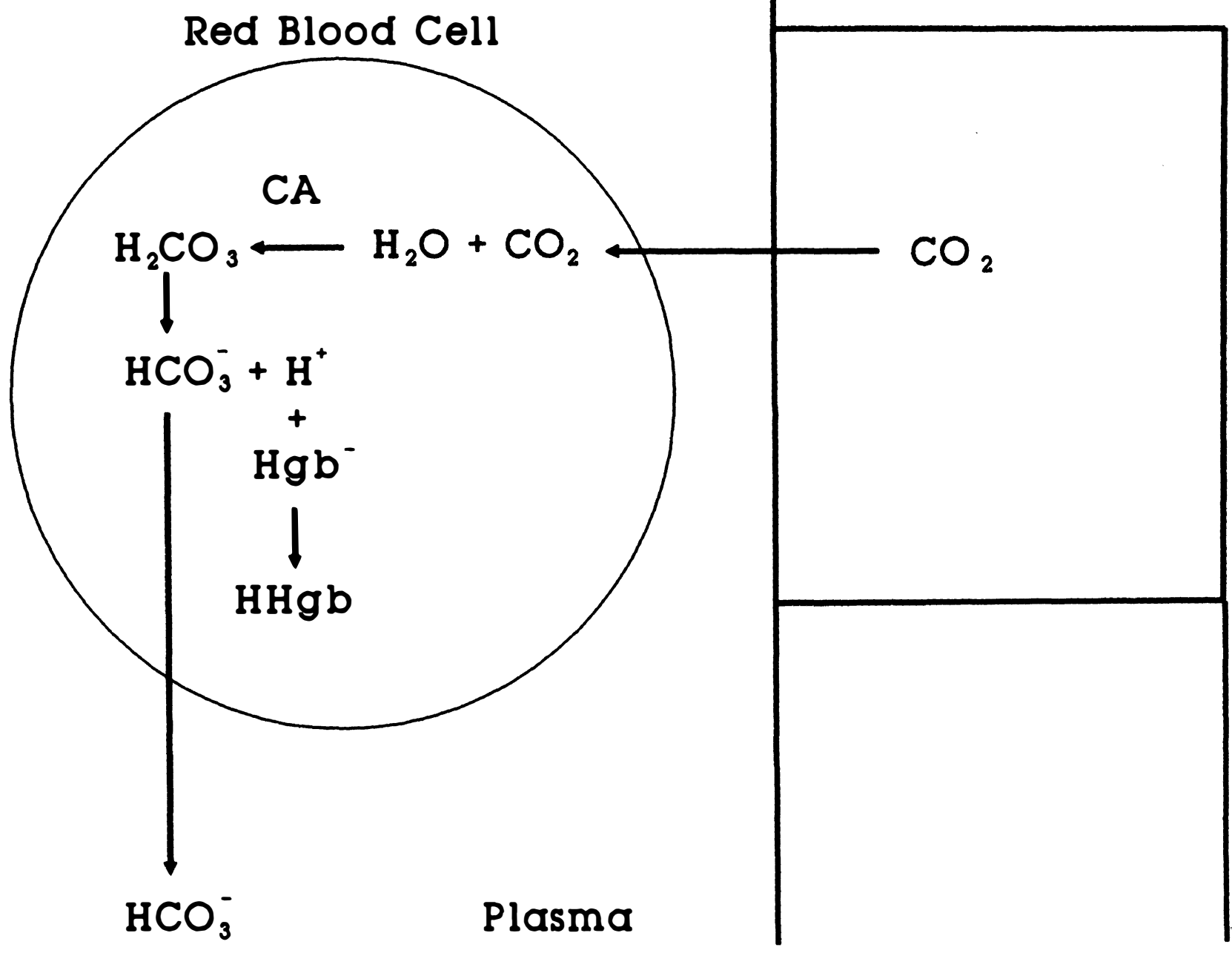

Fig. 2. Action of acetazolamide in the red blood cells at tissue level. Tissue $\mathrm{CO}_{2}$ diffuses into the red blood cells; its combination with water catalysed by carbonic anhydrase $(\mathrm{CA})$ produces bicarbonate $\left(\mathrm{HCO}_{3}^{-}\right)$and hydrogen $\left(\mathrm{H}^{+}\right)$ions. While the bicarbonate ions diffuse out of the red blood cell into the plasma, the hydrogen ions are buffered by the anionic haemoglobin $\left(\mathrm{Hgb}^{-}\right)$. This favours the diffusion of more $\mathrm{CO}_{2}$ out of the tissues and into the red blood cells. 


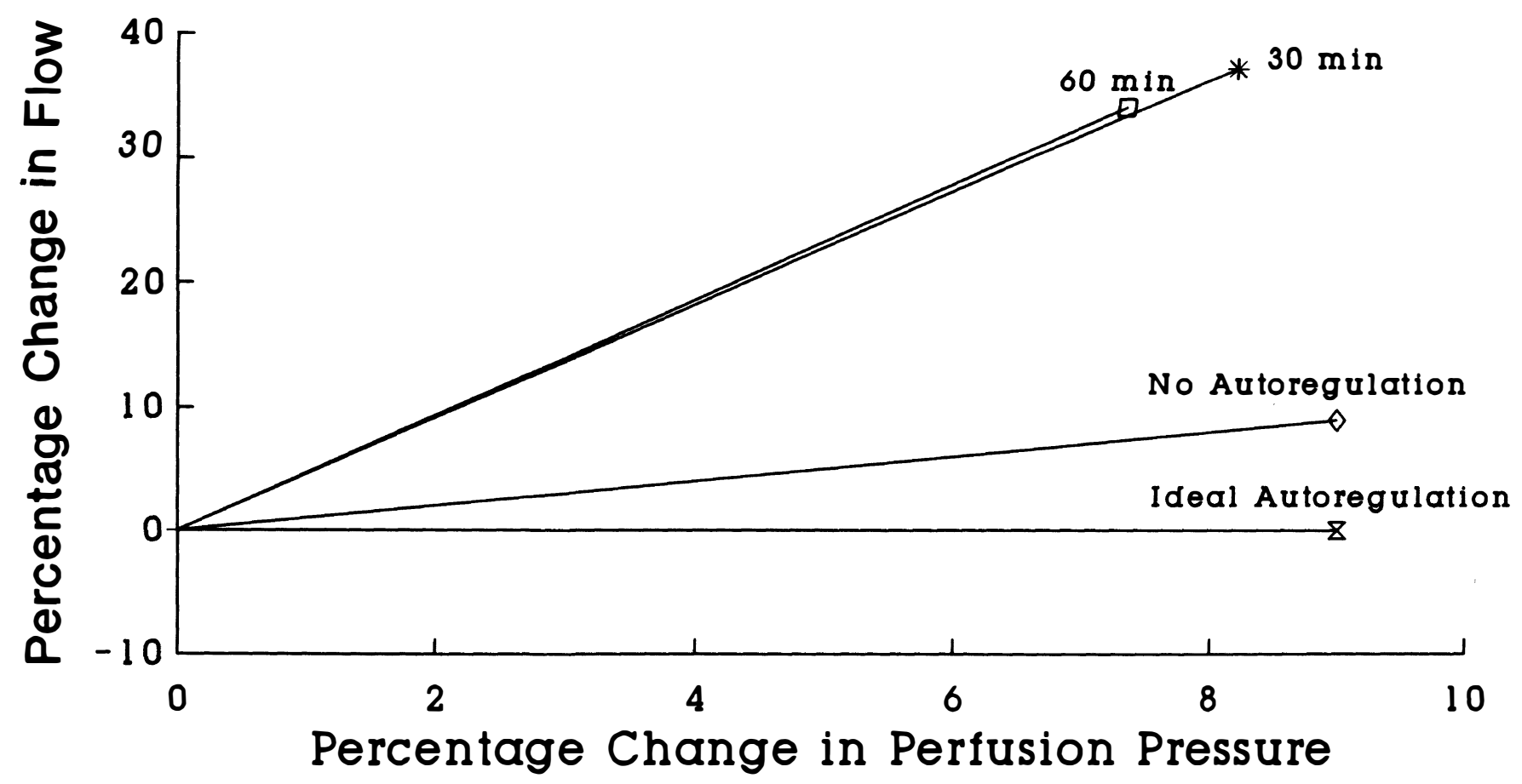

Fig. 3. Percentage change in retinal blood flow'versus the percentage change in retinal perfusion pressure. Ideal autoregulation is when there is no change in flow for a given increase in perfusion pressure. No autoregulation is when the increase in flow is the same as the increase in perfusion pressure. After acetazolamide injection the increase in flow is greater than the increase in perfusion pressure indicating a breakdown in autoregulation.

diffuses out of the red blood cells and contributes to the plasma buffering system, the $\mathrm{H}^{+}$are buffered by the anionic haemoglobin. This process favours the combination of more $\mathrm{CO}_{2}$ with water and therefore more $\mathrm{CO}_{2}$ is removed from the tissues. In the lungs the reverse is true since the $\mathrm{PCO}_{2}$ is lower in the alveoli. Inhibition of carbonic anhydrase will reduce the capacity of the red blood cells to carry $\mathrm{CO}_{2}$, increasing tissue $\mathrm{PCO}_{2} .{ }^{6}$ In the retina, the autoregulatory response to local hypercapnia is vasodilatation, in order to increase tissue blood flow, washing out the excess $\mathrm{CO}_{2}{ }^{7}$ Inhibition of carbonic anhydrase in the kidney causes the loss of $\mathrm{HCO}_{3}{ }^{-}$with resultant metabolic acidosis. The acidosis further stimulates vasodilatation. Retinal haemodynamic consequences of acetazolamide may therefore be due to regulation of the retinal circulation to these metabolic stimuli. Retinal autoregulation to the effect of acetazolamide on retinal perfusion pressure also needs to be considered.

In this study there was vasodilatation in the retinal vasculature by $1.7 \%$ at 30 minutes and $1.9 \%$ at 60 minutes after the injection of acetazolamide. The vasodilatation on its own would contribute to an increase in retinal blood flow by a factor of $3.5 \%$ at 30 minutes and a factor of $3.8 \%$ at 60 minutes since the diameter values are squared in calculating the flow (equation 2). However, the increase in retinal blood flow was $37.0 \%$ at 30 minutes and $34.1 \%$ at 60 minutes; therefore the contribution of vascular dilatation to the increased retinal blood flow was minimal compared with the increase in red cell velocity.

The increase in perfusion pressure achieved was due to a reduction in intraocular pressure. There was a significant decrease in the diastolic blood pressure at 60 minutes after injection but not at 30 minutes. This reduction in the diastolic blood pressure is the result of peripheral vasodilatation as a consequence of the metabolic changes as described above. The slight recovery of ocular perfusion pressure seen at 60 minutes is due to the decaying effect of acetazolamide, since the maximal average response of acetazolamide is achieved 25 minutes after injection. ${ }^{3}$

In order to understand the effect of acetazolamide on retinal vascular autoregulation, the metabolic and retinal perfusion effects of acetazolamide have to be examined separately. When retinal perfusion pressure is increased, autoregulation would be expected to maintain relative constancy of flow. The changes in retinal blood flow are plotted against the changes in perfusion pressure in Fig. 3. In a situation where there is ideal autoregulation there will be no change in flow for a given change in perfusion pressure. ${ }^{10}$ Where there is no autoregulation, such as in a rigid tube system, the increase in flow would increase linearly with the increase in perfusion pressure as defined in Poiseuille's law. Previous work indicates that with up to a $27 \%$ increase in retinal perfusion pressure, retinal blood flow increases only by $7.8 \% .^{24}$ In this study the increase in flow was approximately 4.6 times the increase in perfusion pressure. The increase in retinal blood flow with acetazolamide must be due mainly to its metabolic effects described above.

Grunwald et $a .^{25}$ found no change in macular blood flow after an oral dose of acetazolamide, as measured with a blue light entoptoscope. In their study the systemic acetazolamide dose was raised slowly by giving it orally. That may have produced a suboptimal inhibition of carbonic anhydrase and allowed more time for the macular cir- 
culation to autoregulate, as postulated in the discussion in Grunwald et al. In our study the systemic dose was raised quickly by giving it intravenously. This produces a greater degree of inhibition of carbonic anhydrase, forcing retinal vascular autoregulation to its limits. Also, in Grunwald's study, only macular blood flow was determined, which may have a better autoregulatory capacity than the rest of the retina, since it is the area with the highest metabolic rate. $^{19,20}$

In acute glaucoma there is a precipitous decrease in ocular perfusion pressure. With respect to the formula for the calculation of retinal perfusion pressure, a subject with a normal mean arterial blood pressure of $100 \mathrm{mmHg}$ and a normal intraocular pressure of $20 \mathrm{mmHg}$ would have a retinal perfusion pressure of $47 \mathrm{mmHg}$. When the intraocular pressure rises to $50 \mathrm{mmHg}$ in acute glaucoma, retinal perfusion pressure drops to $17 \mathrm{mmHg}$. This would result in reduced retinal blood flow and retinal ischaemia. This is a consequence of retinal vascular autoregulation at low perfusion pressures failing to maintain retinal blood flow. ${ }^{26}$ Intravenous acetazolamide is therefore useful in the management of acute glaucoma via two mechanisms: firstly by reducing the intraocular pressure and therefore increasing retinal perfusion pressure, and secondly by its metabolic autoregulatory response in increasing retinal blood flow.

In conclusion, acetazolamide causes an increase in retinal blood flow in the human retinal circulation. This provides a rationale for its use in glaucoma.

Key words: Acetazolamide, Autoregulation, Laser Doppler velocimetry, Retinal blood flow.

\section{REFERENCES}

1. ffytche TJ. A rationalization of treatment of central retinal artery occlusion. Trans Ophthalmol Soc UK 1974;94: 468-79.

2. Vorstrup S, Henriksen L, Paulson OB. Effect of acetazolamide on cerebral blood flow and cerebral metabolic rate for oxygen. J Clin Invest 1984;74:1634-9.

3. Hauge A, Nicolaysen G, Thoresen M. Acute effects of acetazolamide on cerebral blood flow in man. Acta Physiol Scand 1983;117:233-9.

4. Bonte FJ, Devous MD, Reisch JS. The effect of acetazolamide on regional cerebral blood flow in normal human subjects as measured by single-photon emission computed tomography. Invest Radiol 1988;23:564-8.

5. Friberg L, Kastrup J, Rizzi D, Jensen JB, Lassen NA. Cerebral blood flow and end-tidal $\mathrm{pCO}_{2}$ during prolonged acetazolamide treatment in humans. Am J Physiol 1990; 258:H954-9.

6. Bickler PE, Litt L, Banville DL, Severinghaus JW. Effects of acetazolamide on cerebral acid-base balance. J Appl Physiol 1988;65:422-7.

7. Tsacopoulos M, Nobel JD. The effect of arterial $\mathrm{pCO}_{2}$ on relative retinal blood flow in monkeys. Invest Ophthalmol 1973; 12:335-47.
8. Ehinger B. Adrenergic nerves to the eye and to related structures in man and the Cynomolgus monkey. Invest Ophthalmol 1966;5:42-52.

9. Laties AM. Central retinal artery innervation: absence of adrenergic innervation to the intraocular branches. Arch Ophthalmol 1967;77:405-9.

10. Johnson PC. Origin, localisation and homeostatic significance of autoregulation in the intestine. Circ Res (Suppl) 1964;15:225-32.

11. Guyton AC, Ross JM, Carrier O, Walker JR. Evidence for tissue oxygen demand as the major factor causing autoregulation. Circ Res 14/15 (Suppl) 1964;1:60-9.

12. Feke GT, Goger DG, Tagawa H, Delori FC. Laser Doppler technique for absolute measurement of blood speed in retinal vessels. IEEE Trans Biomed Eng BME 1987;34: 673-80.

13. Baker M, Wayland H. On-line volume flow rate and velocity profile measurement for blood in microvessels. Microvasc Res 1974;7:131-43.

14. Chen HC, Wiek J, Rassam S, Patel V, Kohner EM. Retinal vessel diameter changes in the cardiac cycle (abstract). Invest Ophthalmol Vis Sci 1992;33:811.

15. Delori FC, Gragoudas ES, Francisco R, Pruett RC. Monochromatic ophthalmoscopy and fundus photography. Arch Ophthalmol 1977;95:861-8.

16. Newsom RBS, Paul MS, Rassam SMB, Jagoe R, Kohner EM. Retinal vessel measurement: comparison between observer and computer driven methods. Graefe's Arch Clin Exp Ophthalmol 1992;230:221-5.

17. Bengtsson B, Krakau CET. Some essential optical features of the Zeiss fundus camera. Acta Ophthalmol (Copenh) 1977;55:123-31.

18. Feke GT, Tagawa H, Deupree DM, Goger DG, Sabag J, Weiter JJ. Blood flow in the normal human retina. Invest Ophthalmol Vis Sci 1989;30:58-65.

19. Riva CE, Grunwald JE, Sinclair SH, Petrig BL. Blood velocity and volumetric flow rate in human retinal vessels. Invest Ophthalmol Vis Sci 1985;26:1124-32.

20. Alm A, Bill A. Ocular and optic nerve blood flow at normal and increased intraocular pressure in monkeys (Macaca irus): a study with radioactively labelled microspheres including flow determinations in brain and some other tissues. Exp Eye Res 1973;15:15-29.

21. Damon DN, Duling BR. A comparison between mean blood velocities and center-line red cell velocities as measured with a mechanical image streaking velocimeter. Microvasc Res 1979;17:330-2.

22. Alm A, Bill A. Ocular circulation. In: Moses RA, Hart WM Jr, editors. Adler's physiology of the eye. 8th ed. St. Louis: CV Mosby, 1987:183-203.

23. Maren TH. Use of inhibitors in physiological studies of carbonic anhydrase. Am J Physiol 1977;232:F291-7.

24. Rassam SMB, Patel V, Newsom RBS, Wiek J, Kohner EM. The effect of blood glucose on retinal autoregulation in diabetic subjects in response to an increase in perfusion pressure. Invest Ophthalmol Vis Sci 1992;33:1366.

25. Grunwald JE, Zinn $\mathrm{H}$. The acute effect of oral acetazolamide on macular blood flow. Invest Ophthalmol Vis Sci 1992;33: 504-7.

26. Riva CE, Grunwald JE, Petrig BL. Autoregulation of human retinal blood flow: an investigation with laser Doppler velocimetry. Invest Ophthalmol Vis Sci 1986;27:1706-12. 